\title{
0 Conhecimento especializado do professor que ensina Matemática no manual didático brasileiro do primeiro ano do Ensino Fundamental
}

\author{
Camila Fernanda Pereira da Luz \\ Edvonete Souza de Alencar
}

\begin{abstract}
Resumo: 0 artigo é uma pesquisa bibliográfica descritiva qualitativa, do manual didático ÁPIS do primeiro ano do ensino fundamental, mais distribuído nas escolas públicas no ano de 2018 segundo dados do PNLD. Buscamos notar os subdomínios do modelo MTSK, presentes nas diretrizes do manual para os professores. Separamos dois trechos de cada unidade de conteúdo apresentada no manual, retiramos e evidenciamos as partes encontradas justificando-as, de acordo com o subdomínio equivalente. Os subdomínios encontrados em maior número, são os pertencentes ao MK, que permite ao professor ensinar os alunos a matemática como um conjunto de regras próprias e estruturada, podendo ser aplicada em qualquer nível de aprendizado do aluno.
\end{abstract}

Palavras-chave: Professor de Matemática. Manual Didático. Anos Iniciais do Ensino Fundamental. Ensino de Matemática.

\section{The specialist knowledge of the mathematics teacher in the brazilian didactic manual of the first year of Elementary School}

Camila Fernanda Pereira da Luz Graduanda de Pedagogia da Universidade Federal da Grande Dourados (UFGD), Dourados, Mato Grosso do Sul, Brasil.

http://orcid.org/0000-0002-7347-8780

\} \text { camila.ademir21@gmail.com }

Edvonete Souza de Alencar Doutorando em Educação Matemática pela Pontifícia Universidade Católica de São Paulo (PUC-SP). Professora da Universidade Federal da Grande Dourados (UFGD), Dourados, Mato Grosso do Sul, Brasil.

https://orcid.org/0000-0002-5813-8702

\edvonete.s.alencar@hotmail.com

Recebido em 19/09/2020 Aceito em 28/11/2020 Publicado em 03/12/2020
Abstract: The article is a qualitative descriptive bibliographic search, from the ÁPIS didactic manual of the first year of elementary school, more distributed in public schools in 2018 according to PNLD data. We seek to note the subdomains of the MTSK model, present in the guidelines of the manual for teachers. We separated two excerpts from each content unit presented in the manual, removed and highlighted the parts found justifying them, according to the equivalent subdomain. The subdomains found in greater number are those belonging to MK, which allows the teacher to teach students mathematics as a set of specific and structured rules, which can be applied at any level of student learning.

Keywords: Mathematics teacher. Didactic Manual. Early Years of Elementary School. Mathematics teaching.

\section{El conocimiento especializado del profesor que enseña matemáticas en el manual didáctico brasileño del primer año de la escuela primaria}

Resumen: El artículo es una búsqueda bibliográfica descriptiva cualitativa, del manual didáctico ÁPIS del primer año de la escuela primaria, más distribuido en las escuelas públicas en 2018 según datos del PNLD. Buscamos señalar los subdominios del modelo MTSK, presentes en las directrices del manual para profesores. Separamos dos extractos de cada unidad de contenido presentada en el manual, eliminamos y resaltamos las partes encontradas que las justifican, según el subdominio equivalente. Los subdominios que se encuentran en mayor número son los pertenecientes a MK, lo que permite al docente enseñar a los estudiantes las matemáticas como un conjunto de reglas específicas y estructuradas, que pueden aplicarse en cualquier nivel de aprendizaje del estudiante.

Palabras clave: Profesor de matemáticas. Manual didáctico. Primeros años de la escuela primaria. Enseñanza de las matemáticas. 


\section{Introdução}

Neste artigo objetiva-se analisar o manual do livro didático do primeiro ano do ensino fundamental mais utilizado no Brasil no ano de 2018, a luz do modelo de Conhecimento Especializado de Professores que Ensinam a Matemática (MTSK), para entendermos os conhecimentos esperados dos professores que ensinam Matemática, além de verificar quais os principais subdomínios ${ }^{1}$ do MTSK ficam evidenciados no manual que visa auxiliar a prática do professor em sala de aula, mediante a execução das atividades propostas no mesmo.

O projeto de iniciação científica faz parte de uma rede maior de investigações e de análise de manuais didáticos ibero americanos, cada análise é realizada inicialmente por ano de ensino da Educação Básica. Após os levantamentos feitos percebemos o livro ÁPIS como o mais distribuído em toda a rede de ensino público brasileiro, segundo dados no Programa Nacional do Livro e do Material Didático-PNLD de 2018. A coleção ÁPIS é um projeto que contextualiza os conceitos específicos em cada área do conhecimento, o manual do primeiro ano do ensino fundamental é um livro didático consumível de caráter pedagógico, utilizado para auxiliar na alfabetização matemática. Logo notamos a relevância de seu papel, como recurso base em diferentes regiões do país, o livro além de trazer as orientações da Base Nacional Comum Curricular - BNCC (BRASIL, 2017) atual e das diretrizes educacionais vigentes que são utilizadas no manual, mas não evidenciaremos em nossa investigação. 0 manual traz os conhecimentos que serão mobilizados, pelo professor que o utiliza; isso nos permite observar o currículo oficial escolar e as metodologias utilizadas para a efetivação de um currículo real² e possível, na construção de uma educação integral que visa a constituição cidadã das crianças e a formação de qualidade, rica em conceitos, promovendo conhecimento especifico desde os anos iniciais do ensino fundamental , apoiando o professor em sua prática.

Assim, a questão que norteou nosso estudo foi: "Quais são os subdomínios do MTSK que mais aparecem nas orientações do manual didático do primeiro ano, do livro ÁPIS de Matemática"?. Destacaremos os trechos em que aparecem os subdomínios, que provavelmente serão utilizados pelos professores, na aplicação das atividades. Organizamos este artigo apresentando o referencial teórico, a metodologia utilizada e as análises para demonstrar a

\footnotetext{
1 SUBDOMÍNIO: subdivisão ou ramificação do domínio principal, MK ou PCK.

2 CURRÍCULO REAL: acontece dentro da sala de aula com professores e alunos a cada dia em decorrência de um projeto pedagógico e dos planos de ensino; sendo um conjunto de experiências, de tarefas, de atividades, que geram ou que se supõe aprendizagem. (BORGES, 2014, p. 11)
} 
presença dos subdomínios e, assim confirmar o objetivo, e assim evidenciar os elementos que são passados pelos professores e absorvidos pelos alunos, mediante classificação pelo modelo MTSK.

\section{0 modelo MTSK: nosso referencial teórico}

O MTSK visa investigar os tópicos do Conhecimento Especializado de Professores que Ensinam a Matemática, com o modelo podemos verificar a prática de ensino e quais são os subdomínios que se destacam. Assim, podemos criar estratégias para analisar e auxiliar os profissionais que estão em sala de aula, não de maneira avaliativa, mas a luz do conhecimento interpretativo, em busca de melhorias para a sua formação e desenvolvimento, focado sempre no praticante.

O grupo de pesquisa que elaborou o MTSK, era composto por professores que atuavam em diferentes níveis de escolarização, além de pesquisadores da área Matemática, e seu objetivo inicial era de "identificar o tipo de aprendizado e as oportunidades criadas pelos professores no decorrer de seu trabalho." (CARRILLO et al., 2018, p. 2). Assim surgiu o MTSK, a partir do modelo Conhecimento Matemático para o Ensino (Content Knowledge for Teaching - MKT) e das abordagens de Deborah Loewenberg Ball, sobre o processo de ensino "O grupo fez uma interpretação da abordagem para explorar o conhecimento especializado dos professores de matemática, com o objetivo de desenvolver um modelo que permita que esse conhecimento seja analisado em profundidade" (CARRILLO et al., 2018).

Partindo do pressuposto que o professor precisa seguir uma linha de conhecimentos específicos matemáticos, e conhecimentos específicos sobre as características inerentes à aprendizagem para exercer seu trabalho, o MTSK é o estudo do conhecimento que o professor utiliza para suas ações de ensino, para isso "é importante que professores de/que ensina Matemática trabalhem conceitos matemáticos corretamente com material construído e pesando para tal fim e articulado, necessariamente, com o conteúdo que ele usa na sua prática da sala de aula." (RIBEIRO, MAMORE, ALENCAR, 2019, p. 57)

O modelo MTSK é dividido em duas grandes áreas necessárias para seu desempenho, o conhecimento matemático3 (MK) e o conhecimento pedagógico do conteúdo (PCK), que podemos associar também ao conhecimento sobre o ensino e sobre a aprendizagem dos tópicos de conteúdo matemático. Cada grande área do modelo se subdivide em três subdomínios específicos

\footnotetext{
${ }^{3}$ As siglas referentes ao modelo apresentadas no artigo, estão em inglês, devido a fundamentação utilizada, com base na leitura do texto original: The mathematics teacher's specialised knowledge (MTSK) model,
} 
do conhecimento, mas além dos conteúdos e tópicos, para a prática do professor o modelo acredita que existem influencias inerente as crenças dos mesmos, isso envolve as crenças do professor sobre a Matemática e como ensiná-la, esta especificidade está representado ao centro do modelo em questão.

Tendo em vista que o conhecimento matemático é constituído por regras estruturais próprias e estabelece conexões especificas para seus procedimentos, o MK se divide nas seguintes categorias: conhecimento dos tópicos matemáticos (KOT), conhecimento da estrutura da Matemática (KSM) e conhecimento da prática Matemática (KPM). Todos esses subdomínios são extremamente necessários para o professor que a ensina, mas no modelo em questão buscou-se enfrentar algumas limitações encontradas nos modelos anteriores como MKT por exemplo. O KOT é referente ao saber profundo que o professor necessita ter a respeito do que será ensinado, as regras, conceitos e os significados presentes em cada conteúdo que será abordado.

O KSM considera as conexões inter-conceituais, ou seja, "questões de sequenciamento que produzam conexões associadas a um aumento na complexidade ou na simplificação; e considerações de demarcação de objetos matemáticos" (CARRILLO et al., 2018, p. 8).

O KPM foca a prática da Matemática como a funcionalidade da mesma, inclui 0 conhecimento sobre a demonstração e a compreensão lógica realizada pelo professor e não apenas no processo de ensiná-la, esse saber pode ser generalizado ou específico de acordo com o conteúdo que está sendo trabalhado. Deste modo destacamos aqui a importância do diálogo entre os subdomínios do MK, se refletem na prática do professor em sala de aula, o conhecimento especializado ajuda a correlacionar os conteúdos específicos com exemplos, tornando 0 aprendizado mais dinâmico para os alunos de forma clara e objetiva.

O PCK engloba os conhecimentos pedagógicos necessários para o ensino matemático, representa o conjunto de conhecimentos, porém precisa ser complementado pelo MK, para que possamos ter uma prática de um ensino eficaz segundo o modelo. Esta área se divide nos seguintes subdomínios: Conhecimento de Características da Aprendizagem Matemática (KFLM), o Conhecimento do Ensino de Matemática (KMT) e o Conhecimento das Normas de Aprendizagem de Matemática (KMLS). O KFLM abrange o conhecimento dos recursos necessários para o ensino matemático e exige do professor que ele saiba como os alunos constroem os conhecimentos matemáticos ao lidar com as atividades propostas por ele, engloba o conhecimento também de estratégias ligadas aos conteúdos de forma específica. 
O KMT este conhecimento se associa ao saber teórico tanto pessoal quanto institucional do professor, embasado em leituras, pesquisas, e reflexão de sua prática, é oriundo de diversas fontes, mas deve ser pensado para o ensino específico.

O KMLS pode ser representado por instrumentos pensados para medir a capacidade de compreensão do aluno de acordo com o nível escolar em que se encontra, podendo ser visualizado nos objetivos esperados de um conteúdo matemático específico, em conjunto com 0 que 0 aluno trabalhou anteriormente e também o que virá a seguir, logo percebemos que estes subdomínios fazem com que o professor que ensina Matemática tenha uma prática mais completa se associado aos domínios pertencentes do MK, o conhecimento pedagógico existente aqui se dissocia da metodologia geral de ensino, necessária para o entendimento dos conteúdos e traz noções específicas da disciplina a serem utilizadas em sala de aula.

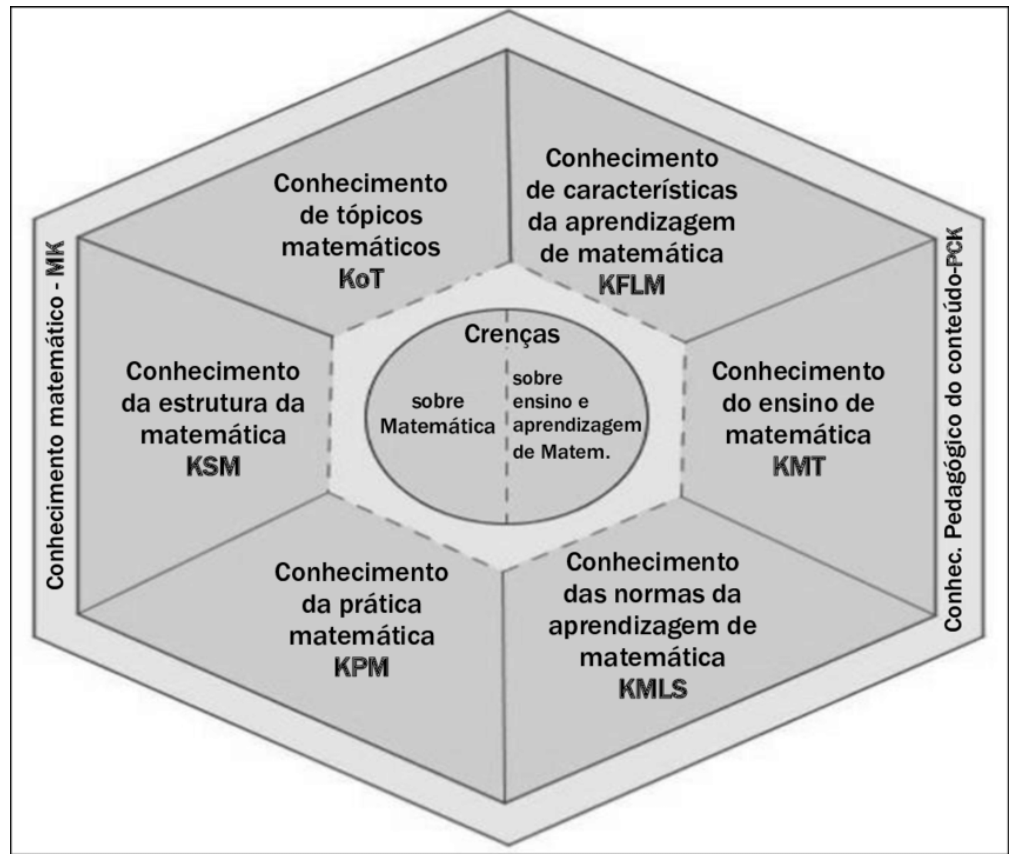

Figura 01: Quadro de subdomínios do MTSK. (MORIEL JUNIOR, J. G., 2014)

Não utilizaremos as crenças para a nossa pesquisa, acreditamos que o estudo das crenças perpassa por todos os subdomínios, por ocupar o centro do modelo apresentado. Contudo, evidenciaremos o estudo dos tópicos pertencentes ao MK e PCK, presentes nas diretrizes do manual didático escolhido para análise. Com base no que se refere ao conhecimento especializado, que o professor precisaria ter a disposição para a realização das atividades propostas, com o intuito de serem trabalhadas no Primeiro Ano do Ensino Fundamental. 


\section{Metodologia}

A pesquisa faz parte de uma análise documental de cunho qualitativo, exploramos os conceitos disponibilizados no modelo de conhecimento especializado do professor, entendemos 0 que o manual didático em questão prioriza, e evidenciamos trechos que aparecem os subdomínios, justificando o conhecimento especializado presente em nossa investigação.

O que cada pessoa seleciona para "ver" depende muito de sua história pessoal e principalmente de sua bagagem cultural. Assim, o tipo de formação de cada pessoa: 0 grupo social a que pertence, suas aptidões e predileções fazem com que sua atenção se concentre em determinados aspectos da realidade, desviando-se de outros. (LÜDKE; ANDRÉ,1986, p. 25)

Portanto, segundo o modelo o que o professor deixa fluir em sua aula, sobre os conhecimentos matemáticos, estão também ligadas as suas crenças, que estão expostas ao centro do MTSK, e ao conhecimento construído ao longo de sua vida pessoal e institucional. Essas influências podem ser encontradas tanto no pesquisador busca resposta nas ações do professor, quanto no profissional que utiliza o manual como recurso para seu trabalho. Sobre a análise documental Lüdke e André (1986) nos orienta:

Embora pouco explorada não só na área de educação como em outras áreas de ação social, a análise documental pode se constituir numa técnica valiosa de abordagem de dados qualitativos, seja complementando as informações obtidas por outras técnicas, seja desvelando aspectos novos de um tema ou problema. (LÜDKE; ANDRÉ,1986, p. 38)

Portanto, utilizando-se do método qualitativo na análise documental, podemos criar estratégias que auxiliem na prática do professor. Construir novas técnicas trabalhando os subdomínios com o professor, fazê-lo entender a complexidade do ato de ensinar a Matemática, e quais suas implicações na formação do aluno, com o investimento na formação inicial e continuada do docente, poderemos então criar meios para a qualidade do ensino e aprendizagem na escola.

Embora sejam de extrema importância as pesquisas na área da Educação Matemática, com foco na formação continuada dos professores, tem tido suas ações no âmbito de seu trabalho prático e não no planejamento. Com o conhecimento especializado do modelo MTSK podem ser explorados atividades e para a realização de formações mais completas e com objetivos específicos, necessários para o professor. Claro que temos restrições, o modelo é novo, podem surgir adaptações ou melhoramento com o passar dos anos e o avanço das pesquisas, porem podemos dar início a essas e outras investigações a partir de suas concepções. A análise feita por meio de leituras e discussões do objeto de pesquisa (manual do professor), juntamente com as contribuições grupo de pesquisa TeiaMat da Universidade Federal da Grande Dourados - UFGD. 
Assim organizamos esse quadro com as atividades de análises desenvolvidas durante a investigação de Iniciação Científica (PIBIC):

- Leitura geral

- $\quad$ Leitura parte específica

- $\quad$ Seleção

- $\quad$ Categorização

- $\quad$ Análise

- $\quad$ Escrita

\section{0 conhecimento especializado do professor no manual analisado}

Como já citado anteriormente organizamos nossas análises identificando inicialmente a parte geral e posteriormente a parte específica por unidade de conteúdo.

\subsection{Análise parte geral}

Como proposto na pesquisa analisaremos o manual didático e as suas diretrizes para a realização das tarefas propostas para os alunos. Durante a primeira análise que fizemos destacamos as páginas 72 e 73 do manual didático. Estas páginas são compostas por orientações gerais sobre o recurso físico da pesquisa, o manual didático do primeiro ano, no início da página 72 vemos uma introdução sobre a coleção inteira e sobre o livro que estamos utilizando. Nos primeiros parágrafos das orientações específicas ficam evidenciados conhecimentos pertencentes as duas grandes áreas descritas no modelo MTSK, que são: o conhecimento matemático e 0 conhecimento pedagógico do conteúdo.

A página 73 mostra uma apresentação do livro e das unidades temáticas com algumas explicações sobre o que e como trabalhar cada unidade. Logo nos primeiros parágrafos quando 0 autor nos apresenta os trechos: "Resgatamos algumas noções; retomamos as noções de; Em seguida trabalhamos." Podemos evidenciar o subdomínio KSM, que considera as conexões interconceituais, que perpassam a sequência do currículo, como no ensino de sequência numérica $(1,2,3 \ldots)$ por meio dos números naturais no primeiro ano, resgatando assim os conceitos já incorporados anteriormente com a contagem e numeração que introduzimos já na Educação Infantil. Notamos também que no parágrafo seguinte o autor inicia a frase "Evitamos a formalização precoce; exploramos; estimulando os alunos; limitamos para que o aluno seja levado a construir." (DANTE, 2016, p. 73). Identificamos aqui o subdomínio KFLM, que exige que o professor saiba 
como os alunos entendem diferentes itens de um determinado tópico e compreendem o raciocínio matemático.

Quando verificamos os trechos "a unidade temática Grandezas e medidas também é trabalhada informalmente, por meio de problematizações e situações do cotidiano." "A ênfase foi dada à construção e a compreensão das primeiras ideias"; "procuramos atividades que estimulassem, respeitassem e incentivassem as hipóteses que 0 aluno tem a cerca de conteúdos matemáticos, possibilitando a ele expressar [...] o caminho de pensamento." (DANTE, 2016, p. 73) Notamos presente em todas as frases, o subdomínio KSLM que possibilita ao professor e ao aluno instrumentos de medição, e da compreensão do aluno em seu nível particular, nota-se 0 conhecimento trazido pelo professor na escolha dos conteúdos que serão ensinados e a mobilização do subdomínio encontrado.

Seguindo ainda na página 73, vemos o subtítulo: "Páginas introdutórias", que remetem ao professor o início do livro, a parte de atividades que esta antes do manual; porém com especificações sobre cada unidade temática que será proposta aos alunos, nas diretrizes do manual o autor orienta-nos a apresentar a estrutura conceitual antes de iniciar o trabalho, e nos mostra como trabalhar desta forma, respeitando uma cronologia hierárquica sobre o que será ensinado em sala de aula, ou seja, encontramos presente o KMT, pois este subdomínio explora o conhecimento teórico que o professor precisa mobilizar para o ensino da matemática, e está ligado diretamente ao conteúdo específico juntamente com o uso de recursos e estratégias para representá-lo.

Portanto, nos parágrafos anteriores destacamos os inúmeros os subdomínios do modelo MTSK presentes no manual didático, principalmente os que pertence ao domínio MK, é claro que a utilização ou não dos recursos e o alcance dos objetivos perpassa a autonomia do professor, porém quando notamos esses presente no livro podemos trabalhar com a hipótese de quais subdomínios são esperados do professor, de acordo com cada tópico matemático que ele ensina, contudo o próprio professor passa a utilizar a prática reflexiva e o conhecimento interpretativo e especializado no planejamento de suas ações, bem como o currículo e as concepções que podem ser desveladas no decorrer da análise da parte especifica. 


\subsection{Análise parte específica}

\subsubsection{Unidade 1- p. 74-86 vocabulário fundamental ${ }^{4}$.}

Esta unidade introdutória aborda inúmeras atividades e proporciona ao professor diversos exemplo práticos e metodológicos para a investigação e o reconhecimento de quais conceitos já estão internalizados e também o estágio de construção os mesmos, para que possamos assim possa consolidar a formação conceitual de acordo com os conteúdos que serão trabalhados. Vemos na citação abaixo a mobilização do subdomínio KFLM.

Como a criança conviverá sempre com símbolos, sinais e códigos, tanto na Matemática quanto em outras áreas do conhecimento e no seu dia a dia, é importante fazer essa iniciação no primeiro ano para que ela possa compreender o significado de cada um e assim usá-los adequadamente. (DANTE, 2016, p. 79)

Ou seja, é necessário a utilização por parte do professor, o uso do subdomínio KFLMconhecimento das características da aprendizagem matemática, afinal a unidade traz como conteúdo os conceitos de posição, medidas e comparação, noções de sentido e sentido contrário, o que é de extrema importância na introdução dos símbolos do cotidiano da criança nesta fase inicial da vida escolar. Além de seguir com a ideia de "sequência e padrão" neste trecho da unidade, encontramos a explicação de quando abordá-las "é importante fazer a iniciação no primeiro ano". A seguir destacamos uma citação que identificamos na mesma unida, outro subdomínio, o KSM.

0 trabalho com sequencias tem objetivos definidos: colaborar para desenvolver 0 raciocínio lógico da criança, preparando-a para a compreensão da sequência dos números naturais do sistema de numeração com seu princípio posicional, bem como para a compreensão dos algoritmos (...). (DANTE, 2016, p. 82)

A unidade por meio de questionamentos encontrados nos parágrafos introdutórios referente a cada conteúdo, 0 autor explica as atividades presentes no manual didático, pensadas para a facilitação do aprendizado que verificamos nas páginas do livro do aluno. O que nos permite observar e destacar o subdomínio KSM-Conhecimento Da Estrutura Matemática, pois com ele, explorando metodologias diferentes, podemos introduzir de forma gradativa e em conexão com unidades anteriores e posteriores, que podem ser distinguidas de maneira inter-conceitual e intraconceitual. Nas diretrizes seguintes o autor mostra como ensinar um determinado tema

\footnotetext{
4 VOCABULÁRIO FUNDAMENTAL: título da primeira unidade de conteúdo do manual ÁPIS, analisado no artigo.
} 
estimulando a criatividade, e mobilizando o subdomínio KPM-Conhecimento Da Pratica Matemática.

Explore algumas que envolvem o corpo das crianças (características: ser menino ou menina; usar óculos, tênis, boné; cor da pele, dos cabelos, dos olhos; comprimento dos cabelos), os objetos da sala de aula ou do pátio da escola, a natureza (tamanhos, formas, texturas de folhas e flores), preferências das crianças (gostar de esportes, de televisão, de cinema etc.) e outras. (DANTE, 2016, p. 86)

Trabalhando por meio das características como descrito na citação podemos estabelecer conexões do KPM, pois esse subdomínio aborda ações efetivas para o ensino e a aprendizagem e pode envolver os alunos de maneira individual ou em interação com o grupo. Como vimos nesta unidade de maneira mais frequente, o professor utilizaria para ensinar as atividades propostas, os subdomínios presentes no MK-Conhecimento Matemática, mais do que os subdomínios presentes no PCK-Conhecimento Pedagógico Do Conteúdo.

\subsubsection{Unidade 2 - p. 87-100 números até dez}

Nesta unidade vemos atividades com base nos conceitos de classificação, formação de sequencias e correspondência um a um, Dante introduz os conteúdos de maneira resumida para os professores de modo que possam explorar o subdomínio do KMLS, que abrange 0 conhecimento das normas de aprendizagem pedagógica, por exemplo.

\footnotetext{
Nesta unidade trabalhamos a construção da ideia, do conceito do 1, do 2, até $010 \mathrm{e}$ do zero. A construção e a compreensão da ideia de número pressupõem uma série de atividades sobre classificação (separar de acordo com certas características), formação de sequencias (1 menino, 2 meninas, 1 menino, 2 meninas etc.) e correspondências um a um (para identificar onde há mais e onde há menos). 0 estudo dos números até 10 vai permitir as primeiras abordagens de medidas e estatística. (DANTE, 2016, p. 87)
}

Trazemos então a ideia de quantidades inserida nas atividades e experenciamos com os alunos mediante dos exemplos da correspondência de um a um afim de descobrir e explorar agrupamentos, mobilizando o KMLS-Conhecimento das Normas de Aprendizagem da Matemática, além disso Dante, faz representação de quantidades, para analisar o significado de cada número dentro da aula e, explora interdisciplinarmente diferentes conceitos movendo conhecimentos nas diversas áreas estimulando assim o raciocínio lógico. Para que o professor possa trabalhar desta forma é necessário que ele tenha o acesso também ao subdomínio KFLM.

Algumas crianças chegam ao ensino fundamental sabendo dizer os números e, às vezes, até mesmo sabendo escrevê-los. Isto não significa que já tenham construído 0 conceito de número ou de quantidade. Antes de escrever os símbolos, de registrar o conceito, é preciso desenvolver muitas atividades com as crianças para que elas construam esse conceito. (DANTE, 2016, p. 91) 
O KFLM-Conhecimento das Características da Aprendizagem Matemática, está presente no trecho acima, pois devemos saber se conseguimos atingir os objetivos propostos em cada atividade planejada, no decorrer do ano letivo, por parte das crianças, mediante de uma avaliação continua e para isso, o professor pode iniciar primeiro a contagem de partes do corpo e/ou de objetos do meio em que a criança vive. Podendo perceber o que elas sabem previamente. Porém como explicitado nesta idade é importante trabalhar e introduzir ideias, sem a necessidade de se apegar as nomenclaturas. Entender essa diferença exige do professor e da criança um conhecimento mobilizado pelo KPM.

$\mathrm{Na}$ atividade 5 da página 61, será trabalhado o senso crítico do aluno, por meio da análise de várias cenas que contem ou não atitudes cidadãs. Após um diálogo inicial, em que os alunos devem ser estimulados a se expressar, é interessante dirigir a análise de cada cena, auxiliando-os na identificação de práticas corretas ou incorretas do ponto de vista da cidadania. (DANTE, 2016, p. 99)

O KPM- Conhecimento Da Pratica Matemática, que pode ser também associada com as ações e demonstrações de exemplos e contra-exemplos, abordados no dialogo inicial, afim de construir solidamente os conceitos fundamentais esperados da atividade proposta. Logo nesta unidade mobilizamos os subdomínios do PCK-conhecimento pedagógico do conteúdo, ou seja, é mobilizado a o conhecimento da pratica em sala também para o ensino.

\subsubsection{Unidade 3-101-107 a ordem dos números}

Esta unidade aborda o sistema de numeração com exemplos cotidianos e utilizando referências facilitadoras para a fixação da ordem numérica. Percebemos no trecho a seguir 0 subdomínio KPM, pois, por meio de uma receita simples de salada de frutas, podemos introduzir conceitos interdisciplinares, como variedade de cores, texturas sabores presentes nas frutas; e poderíamos acentuar os conceitos de numeração como quantas frutas foram utilizadas, quais as espécies eles já conheciam e fazendo a anotação em formato de lista fortalecendo o conceito esperado de ensino e aprendizagem da unidade.

Faça uma deliciosa salada de frutas ou sucos variados e ofereça um lanche coletivo.
Assim, as crianças podem aproveitar esse momento para experimentar novos
alimentos. Explore a forma e as cores das frutas por dentro e por fora. Nas atividades
1 e 2 da página 82, estimule a escrita espontânea dos alunos. Faça uma lista com as
frutas de que eles gostam e outra com as frutas de que não gostam. Leia e peça aos
alunos que corrijam possíveis erros de suas escritas, comparando a sua com a deles.
Na fase de alfabetização, é preciso estimulá-los a escrever. (DANTE, 2016, p. 105)

Utilizamos a escrita para auxiliar na alfabetização matemática, o subdomínio KPM se faz presente na ação do professor descrita na citação acima, ao praticar uma metodologia diferente, espera-se então que ele mobilize este subdomínio que faz parte do conhecimento especializado. 
Bem como no trecho seguinte se faz presente as atribuições para construir a matemática, identificada no subdomínio KMLS.

Assim como é importante criar um ambiente alfabetizador, em matemática precisamos criar um ambiente aritmetizador. Além das letras, os números fazem parte do dia a dia das crianças. É importante que os tenham à disposição na sala de aula para eu possam recorrer a eles sempre que necessário. (DANTE, 2016, p. 106)

O subdomínio presente aqui está visível na possibilidade que se tem de atribuir sentido a Matemática em qualquer estágio de aprendizado que a criança esteja, por meio de fontes oficiais como os livros didáticos e as atividades orientadas pelo currículo da escola, mas buscando cumprir o conhecimento mínimo esperado de cada conteúdo, explorando também o espaço físico e as situações criadas espontaneamente, como fonte de aprendizado.

\subsubsection{Unidade 4-108-111 figuras geométricas}

Esta unidade traz para os alunos e professores o conteúdo muito rico, para ser trabalhado no primeiro ano, onde podemos explorar inúmeros conceitos e conteúdos de diferentes temáticas. Por isso encontramos o KSM pois faz parte do conhecimento professor e as conexões possíveis entre as unidades. "Na atividade 5, em especial, exige-se a contagem dos sólidos e a marcação das quantidades em uma tabela, o que integra a unidades temáticas Geometria, número e probabilidade e estatística." (DANTE, 2016, p. 110). Como visto essa funcionalidade de conceitualizar demais conceitos com um determinado conteúdo faz parte do KSM. Na mesma unidade encontramos também o KPM, afinal o professor pode envolver todos os alunos individualmente e em interação com determinada pratica, afim de introduzir o pensamento matemático e sua funcionalidade.

Saber localizar-se em uma cidade ou bairro é fundamental, como é explorado nas atividades. Estimule os alunos a contar o trajeto que fazem de casa até a escola ou da sala de aula até a saída da escola. Leve um mapa da região onde está situada a escola e peça a eles que apontem onde ela e outros lugares conhecidos estão localizados. (DANTE, 2016, p. 112)

Com práticas simples de localização como estas encontradas na citação, conseguimos estimular o cálculo espontâneo, nas crianças, sem limitá-los as regras de início, o subdominio KPM consiste no ato de fazer induções e deduções de acordo com o conhecimento prévio dos alunos.

\subsubsection{Unidade 5-112-113 nosso dinheiro}

Esta unidade em geral traz muitas referências do sistema monetário, com brincadeiras e representações do que é a Matemática no cotidiano dos alunos. Por isso encontramos o KOT, faz parte do currículo brasileiro a educação financeira ser inserida desde os anos iniciais. 
Na página 125, introduz-se, na atividade 4 , a representação das quantias usando $R \$$ e virgula. $O$ explorar e descobrir da página seguinte é sobre possibilidades. Os alunos, em dupla, devem encontrar duas possibilidades de obter as quantias 2, 5, 8 e 10 reais. $\mathrm{Na}$ atividade 5 da página 126, são trabalhados informalmente as operações de adição e subtração. (DANTE, 2016, p. 113)

Com propostas como essa descrita acima, notamos como as características do conhecimento profundo do professor sobre determinado conteúdo pode fazer diferença no resultado da aprendizagem e no modo de avaliá-lo. Contudo a conversa com os alunos pode fazer com que o professor mobilize outros subdomínios, como o KSM, encontrado no trecho a seguir.

\begin{abstract}
Aproveite para conversar com os alunos sobre pesquisa de preços, comparação de valores, economia de dinheiro e consumo consciente. Quando forem realizar alguma compra, sugira a eles que se questionem: 'será que eu preciso mesmo disso que quero comprar?'. pergunte aos alunos se algum deles possuem cofrinhos para guardar dinheiro para algo que desejam comprar, etc. (DANTE, 2016, p. 114)
\end{abstract}

Estimulando a pesquisa espontânea fora da escola e a comparação do que aprendemos em sala de aula, com o que presenciamos no dia-a-dia, conseguimos conscientizar os alunos desde o início de sua alfabetização, estimulando-os a fazer as conexões temporais, ajudando na simplificação do conteúdo, formulação de questões cidadãs e noções de economia.

\title{
4.2.6 Unidade 6 - 114-117 adição e subtração
}

Nesta unidade, encontramos muitas atividades que proporcionam para as crianças 0 ensino e a aprendizagem, mediante da experiencia junto com o professor e os colegas, por um período continuo de vivencias, por isso, destacamos o subdomínio KFLM, onde inclui a compreensão dos alunos para o melhor entendimento da matéria, neste caso as operações de adição e subtração, o professor deve estar ciente de como os alunos pensam a Matemática.

Proponha outras atividades concretas como essas das páginas 139 a 141, envolvendo
as próprias crianças e objetos da sala de aula. Por exemplo, chame, ao mesmo tempo,
5 meninos e 4 meninas à frente da sala. Depois, pergunte quantas crianças são ao
todo, juntando meninos e meninas (ideia de juntar quantidades). Em outra situação, 4
crianças estão brincando com blocos. Chegam mais 2 para brincar. Pergunte quantas
crianças ficaram ao todo brincando com os blocos (ideia de acrescentar uma
quantidade a outra). Repita essas atividades usando objetos disponíveis na sala de
aula. (DANTE, 2016, p. 115, grifos nossos)

Essas experiências concretas, auxilia no conhecimento prático do conteúdo, além de envolver as crianças com os conceitos e formas diferentes de calcular para obter um resultado. Encontramos na unidade de conteúdo, o que se espera da atividades propostas em relação ao conjunto de técnicas e modo de ensinar ou aprender um conteúdo, sendo assim, notamos o KMT, afinal, o professor deve conhecer os recursos para poder melhor avaliar, se houve um aprendizagem efetivamente. 
A atividade 2 da página 146 estimula a utilização de estratégias pessoais de resolução. 0 registro por meio do desenho e a socialização das estratégias são fundamentais para a ampliação de repertorio do grupo e serve também como instrumento de sondagem para você, que toma conhecimento do caminho percorrido pelos alunos. (DANTE, 2016, p. 116)

Quando incentivamos as resoluções pessoais, estimulamos a criatividade e o raciocínio lógico, quando permitindo diferentes formas de representar o conteúdo, conseguimos auxilio no conhecimento e na percepção das limitações e avanços no processo de desenvolvimento individual.

\subsubsection{Unidade 7-118-122 números até 100}

Como já citamos o subdomínio KSM, faz conexões Inter conceituais, ou seja, permite estabelecer uma relação mútua entre os conceitos que aparecem nas unidades de conteúdo, por isso, o encontramos e destacamos no trecho seguinte. Nas orientações do manual percebemos um pedido aos professores para mobilizarem esse tópico, fazendo a simplificação dos conteúdos, e a complexidade de conceituarem aproveitando os conhecimentos anteriores e preparando-os para o que vem a depois.

Na atividade 12 dessa pagina faz conexão com a grandeza comprimento, utilizando os passos de uma criança como unidade não padronizada de medida. Peça aos alunos que calculem o comprimento de uma das paredes da sala, utilizando seus passos como unidade de medida. A atividade 13 , também dessa página, estimula a utilização de estratégias pessoais de resolução. (DANTE, 2016, p. 120)

Logo o KSM, está presente, pois além dos conhecimentos já estabelecidos, considera também as conexões temporais como geradoras para aquisição de novos conceitos. Na citação a seguinte identificamos o KPM, que segue de maneira diferente, por considerar a pratica efetiva para as ações de ensino e aprendizagem, onde o papel do professor é essencialmente de orientador, para aquisição do conhecimento.

Aproveite e leia com os alunos os versinhos desta paina. 0 ditado de números da atividade 11 dessa página é importante para avaliar se 0 aluno aprendeu ou não a escrever os números de 0 a 100. Na página 207, deixe que os alunos, em duplas descubram os resultados das adições e subtrações da atividade 12. A atividade 13, também dessa página permite uma integração com a unidade temática probabilidade e estatística. (DANTE, 2016, p. 123)

A metodologia empregada interfere diretamente, no resultado final, e no alcance dos objetivos. A avaliação ocorre de maneira continua, por meio de realização das tarefas simples como a apresentada no ditado da atividade. Em geral nessa unidade predominantemente encontramos os subdomínios pertencentes ao MK do modelo. 


\subsubsection{Unidade 8-123-128 grandezas e medidas}

A unidade final traz um tema importante, e muito utilizado no nosso cotidiano, podemos encontrar essas propriedades matemáticas, nos espaços sociais que frequentamos, como mercados, farmácias entre outros. Por isso, o KOT fica evidenciado, faz parte desse subdomínio os diferentes tipos de registro do conhecimento matemático, como os gráficos, as tabelas e assim por diante. "A importante unidade temática que dá nome a esta unidade é enfatizada em toda coleção, quer por sua aplicação no dia a dia, quer por possibilitar melhor compreensão e aplicabilidade de muito conceitos matemáticos." (DANTE, 2016, p. 123)

Os conceitos e o conteúdo encontrados no manual, podem ser aplicados de forma natural, fazendo com que os conceitos matemáticos sejam aprendidos efetivamente e internalizados. Ensinando de maneira reflexiva, e buscando significado nas exemplificações, podemos diminuir a aversão preexistente da disciplina de matemática nos aos iniciais. No KMT, evidenciado na citação seguinte, notamos o estímulo ao aprendizado com vivências, baseado no concreto, onde a abstração pode ser potencializada, porém com estratégias e reflexões de um conteúdo específico.

\footnotetext{
É importante que os alunos percebam a passagem do tempo- noção abstrata que precisa de estímulos, inclusive corporais. Brincar de pular corda pode ser uma atividade interessante e ajuda-os a perceber o "tempo" que leva até que eles se movimentem novamente para pular a corda que está girando. (DANTE, 2016, p. 127)
}

Nesta unidade encontramos subdomínios presentes no MK e PCK, o professor que consegue mobilizar o conhecimento especializado de forma consciente e os subdomínios e de maneira reflexiva, pode sem dúvida aperfeiçoar cada vez mais a sua prática, com diferentes recursos didáticos, físicos e digitais, fazendo da sua experiencia a práxis, e produto para uma formação continuada completa e um exemplo do conhecimento especializado proposto nas atividades, técnicas e metodologia encontradas no manual analisado.

\section{Algumas considerações}

Considerando as análises, conseguimos encontrar os subdomínios em todas as unidades de conteúdo especifico do manual, podemos concluir que o domínio que mais se destaca são os pertencentes ao $\mathrm{MK}$, onde a matemática é vista como um conhecimento estruturado com regras próprias. Ter um entendimento dessa rede de conexões e regras, "permitem ao professor ensinar o conteúdo de maneira conectada e validar suas conjecturas matemáticas próprias e de seus alunos." (CARRILLO et al., 2018). A vantagem deste diagnóstico é a inclusão de conceitos importantes, que pode ser feita em que qualquer nível de aprendizado escolar em que o aluno esteja. 
Em contrapartida, encontramos o PCK menos evidenciado nas unidades, o que nos leva a refletir sobre o conhecimento da pratica pedagógica do professor que ensina a matemática, afinal este domínio descrito no modelo se preocupa com as maneiras de aprender o conteúdo e com o processo de ensino percorrido por cada aluno, utilizando o que já está construído e atribuindo 0 conhecimento específico por meio de atividades com objetivos e recursos pedagógicos diferentes.

Por se tratar de orientações escritas, devemos entender que cabe a cada professor a utilização ou não dos manuais, além da autonomia do professor devemos enfatizar que ao encontrarmos e destacarmos os subdomínios em nossa análise, não significa que não contenham outros subdomínios no manual. O modelo nos permite identificar a diferenciação do conhecimento matemático e do conhecimento pedagógico do conteúdo, classificando-os em suas subdivisões, como um instrumento de aprimoramento das suas práticas, não com a finalidade de avaliar 0 professor, mas para organização didática do professor por meio deum instrumento privilegiado de conhecimento: o manual didático.

\section{Referências}

BALL, D. L.; THAMES, M. H.; PHELPS, G. Content Knowledge for Teaching: What makes it special? Journal of Teacher Education, v. 59, n. 5, p. 389-407, 2008.

BRASIL. Base Nacional Comum Curricular (BNCC). Educação é a Base. Brasília, MEC/CONSED/UNDIME, 2017.

CARRILLO, Y. J., et al. The mathematics teacher's specialised knowledge (MTSK) model. Research in Mathematics Education. V.20 ed 3, 2018.

DANTE. L. R. Ápis Alfabetização Matemática de $1^{\circ}$ ano - Manual didático do professor. São Paulo: Editora Ática, 2016.

LÜDKE, M.; ANDRÉ, M. E. D. A. Pesquisa em Educação: Abordagens Qualitativas. São Paulo: EPU, 1986.

MORIEL JUNIOR, Jeferson G.. Conhecimento Especializado Para Ensinar Divisão De Frações. 2014. 10.13140/2.1.1314.8965. Disponível em: https://www.researchgate.net/figure/Quadro-8Subdominios-do-MTSK_fig1_272179124 Acesso em: 18 de out. de 2019, às 15:40.

RIBEIRO, M.; MARMORE, J.; ALENCAR, E. S. . Lente Teórica: Mathematics Teacher?S Specialised Knowledge ? Mtsk. In: Edvonete Souza de Alencar. (Org.). Literatura infantil para 0 ensino de Matemática como recurso para a formação de professores. 1ed.Belem: Twee, 2019, v. 1, p. $46-60$. 